\title{
Forest Fire Risk Assessment: An Illustrative Example from Ontario, Canada
}

\author{
W. John Braun, ${ }^{1}$ Bruce L. Jones, ${ }^{1}$ Jonathan S. W. Lee, ${ }^{1}$ \\ Douglas G. Woolford, ${ }^{2}$ and B. Mike Wotton ${ }^{3}$ \\ ${ }^{1}$ Department of Statistical and Actuarial Sciences, The University of Western Ontario, London, \\ Ontario, ON, Canada N6A 5B7 \\ ${ }^{2}$ Department of Mathematics, Wilfrid Laurier University, Waterloo, ON, Canada N2L 3C5 \\ ${ }^{3}$ Faculty of Forestry, The University of Toronto, Toronto, ON, Canada M5S $3 B 3$
}

Correspondence should be addressed to W. John Braun, braun@stats.uwo.ca

Received 2 October 2009; Revised 6 March 2010; Accepted 27 April 2010

Academic Editor: Ricardas Zitikis

Copyright (C) 2010 W. John Braun et al. This is an open access article distributed under the Creative Commons Attribution License, which permits unrestricted use, distribution, and reproduction in any medium, provided the original work is properly cited.

This paper presents an analysis of ignition and burn risk due to wildfire in a region of Ontario, Canada using a methodology which is applicable to the entire boreal forest region. A generalized additive model was employed to obtain ignition risk probabilities and a burn probability map using only historic ignition and fire area data. Constructing fire shapes according to an accurate physical model for fire spread, using a fuel map and realistic weather scenarios is possible with the Prometheus fire growth simulation model. Thus, we applied the Burn-P3 implementation of Prometheus to construct a more accurate burn probability map. The fuel map for the study region was verified and corrected. Burn-P3 simulations were run under the settings (related to weather) recommended in the software documentation and were found to be fairly robust to errors in the fuel map, but simulated fire sizes were substantially larger than those observed in the historic record. By adjusting the input parameters to reflect suppression effects, we obtained a model which gives more appropriate fire sizes. The resulting burn probability map suggests that risk of fire in the study area is much lower than what is predicted by Burn-P3 under its recommended settings.

\section{Introduction}

Fire is a naturally occurring phenomenon on the forested landscape. In Canada's boreal forest region, it plays an important ecological role. However, it also poses threats to human safety and can cause tremendous damage to timber resources and other economic assets.

Wildfires have recently devastated parts of British Columbia, California, and several other locations in North America, Europe, and Australia. The economic losses in terms of suppression costs and property damage have been staggering, not to mention the tragic loss of human life. Many of these fires have taken place at the wildland-urban interfacepredominantly natural areas which are increasingly being encroached upon by human 
habitation. As the population increases in these areas, there would appear to be potential for increased risk of economic and human loss.

A wildland-urban interface is defined as "any area where industrial or agricultural installations, recreational developments, or homes are mingled with natural, flammable vegetation" [1]. The Province of Ontario has several areas which could be classified as wildland-urban interface. These areas include the Lake of the Woods region, the Thunder Bay region, the region surrounding Sault St. Marie, and North Bay among others. One of the most significant of these is the District of Muskoka which is a popular recreational area. This district, located in Southern Ontario (Figure 1), is commonly referred to as "cottage country". It spans 6,475 square kilometers and contains over 100,000 seasonal properties or cottages. Many of these properties are nestled in forested areas, which make up most of the region. This concentration of values is of particular interest to the Canadian insurance industry due to the risk of claims from damage caused by wildfire.

Unlike British Columbia and California where topography plays a major role in the rate of spread of wildfire, Ontario is relatively flat but is dominated geographically by the Boreal and Taiga forests, where some of the largest fires in Canada have burned [2]. The Boreal forest has a large percentage of coniferous trees which are susceptible to high intensity crown wildfires. The Muskoka region is on the southern edge of the Boreal forest, and thus there is potential for substantial property damage from fires originating further north.

We are focusing on the Muskoka region to provide an illustration of how the tools that have been developed by the forest management community can be applied to assess fire risk. The methods described here can be adapted easily to other wildland-urban interface locations. The Muskoka area presents some technical challenges which do not exist to the same degree in most other wildland-urban interface settings.

Although there have not yet been substantial losses due to wildfire in the Muskoka area, it is important to assess the risk because of what is being observed elsewhere (e.g., British Columbia and California) and because of possible climate change effects which could ultimately lead to increased fire activity across Canada.

Wildfires usually start from point ignitions, either by people or by lightning, and if not detected immediately, they can spread rapidly under appropriate weather conditions. Approximately half of the forest fires in Canada are ignited by lightning. Such fires account for approximately 80 percent of area burned [3].

The spread of a wildfire in a particular area depends on many factors but most importantly, it is influenced by local weather, vegetation, and geography [2]. Of these three factors, the geographical features remain static, while vegetation changes gradually over time. In addition, changes in human land use patterns, such as industrial forestry, or urban expansion can lead to changes in vegetation. Weather is the most dynamic factor affecting fire risk. The unpredictable nature of weather makes modelling forest fire spread a difficult task. Nonetheless, the risk of wildfire in a region can be estimated using the methodology described in this paper.

In Canada, the fire season can last from early April through October each year. During this period, the probability of fire ignition and fire spread potential changes depending on the time of year, primarily influenced by seasonal weather patterns. Each year an average of 2.5 million hectares are burned by 8,500 individual wildfires.

Most regions which are within the Boreal and Taiga zones have very accurate and up-to-date fuel information because the provincial fire management agencies maintain these records rigorously. The forest resource inventory information in our study area, and hence the fuel map which is based upon it, is not updated as frequently by the Ontario Ministry of 


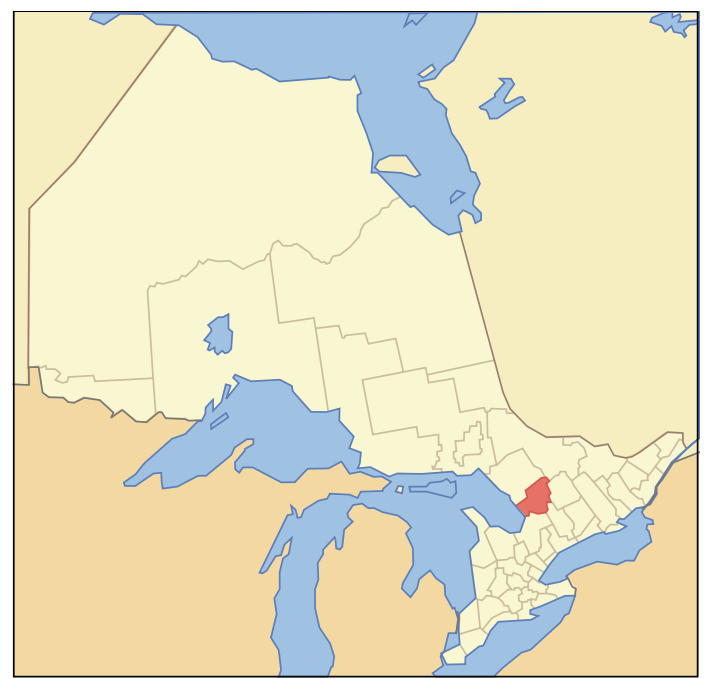

Figure 1: Location of the District of Muskoka within the Province of Ontario.

Natural Resources in this region because there is a higher proportion of private land under municipal fire protection agreements with the province and relatively little area under forest management planning. Thus, it was necessary for us to validate the fuel map by doing a field survey. To apply the methodology in other instances would be straightforward, not requiring this kind of fieldwork.

The remainder of this paper will proceed as follows. The next section provides a description of the study area and the fire data for that region. Section 3 contains results of an ignition risk assessment which uses historic fire data only. This section also contains a crude burn risk assessment.

In Section 4, we briefly describe the Prometheus fire growth model [4] and how it is used in the Burn-P3 simulator [5] to generate a burn probability map. This section also provides a description of the required data inputs and the procedure that was used to obtain and verify this data. In Section 5, the results of the analysis are presented along with a summary of the limitations of this study.

\section{The Data and Study Area}

\subsection{Study Area}

Of the properties in the Muskoka District, the most expensive are concentrated along the shores of the three major lakes: Lake Joseph, Lake Muskoka, and Lake Rosseau. A $25 \times 35 \mathrm{~km}$ rectangular study area that encompasses a large portion of these lakes was selected (Figure 2) for the our study. In order to reduce possible biases near the boundaries of this region, we also considered a 5-km wide "buffer" zone which surrounds the study area. Fires originating in this zone could spread into the study area, and this possibility needs to be accounted for.

\subsection{Description of Historic Fire Data}

Fire data for over 12,200 fires from 1980 through 2007 were obtained for a region encompassing the study area. For each fire, a number of covariates were recorded including 


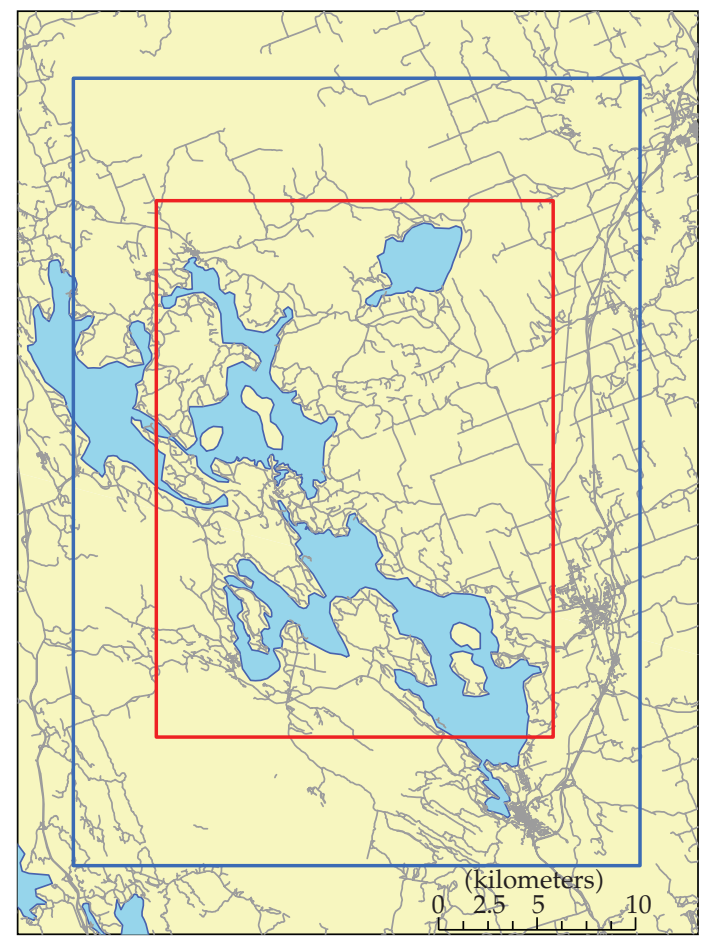

Figure 2: Map illustrating the $25 \times 35 \mathrm{~km}$ study area which is enclosed in the red box as well as the buffer zone used in the Burn-P3 modelling denoted by the blue box.

the date, ignition location, and final area. Figure 3 shows an estimate of the density of the natural log-transformed fire sizes of escaped fires from this dataset. Here, we use the Ontario Ministry of Natural Resources definition of an escaped fire: any fire where final area exceeds 4 hectares. The fuel composition, weather conditions, and fire suppression capabilities for this region are relatively homogeneous and hence are representative of our smaller study area. Within this dataset, 319 fires were located in the study area. Figures 4 and 5 show locations of human-caused and lightning-caused ignitions

\section{Ignition and Burn Probability Modelling Using Generalized Additive Models}

\subsection{Ignition Modelling}

Brillinger et al. [6] provide a method for assessing fire risk in a region using generalized additive models. Their technique uses pixellated data on a fine scale where each pixel is assigned a 1 or a 0 depending on whether or not a fire was ignited at that location. (To be precise, they considered temporal effects as well, while our focus will be to produce only a spatial risk map.) The resulting data set is very large with an overwhelming proportion of $1 \times 1 \mathrm{~km}$ pixels (sites) without a fire ignition between 1980 and 2007, indicated by a value of 0 . However, a simple random sample of these 0 -sites can be analyzed in the same way as the full dataset with the addition of an offset of the form $\log \left(1 / \pi_{s}\right)$. Here $\pi_{s}$ denotes the (constant) inclusion probability for site $s=\left(s_{1}, s_{2}\right)$, where $s_{1}$ and $s_{2}$ refer to the easting and northing geographic coordinates, respectively. 


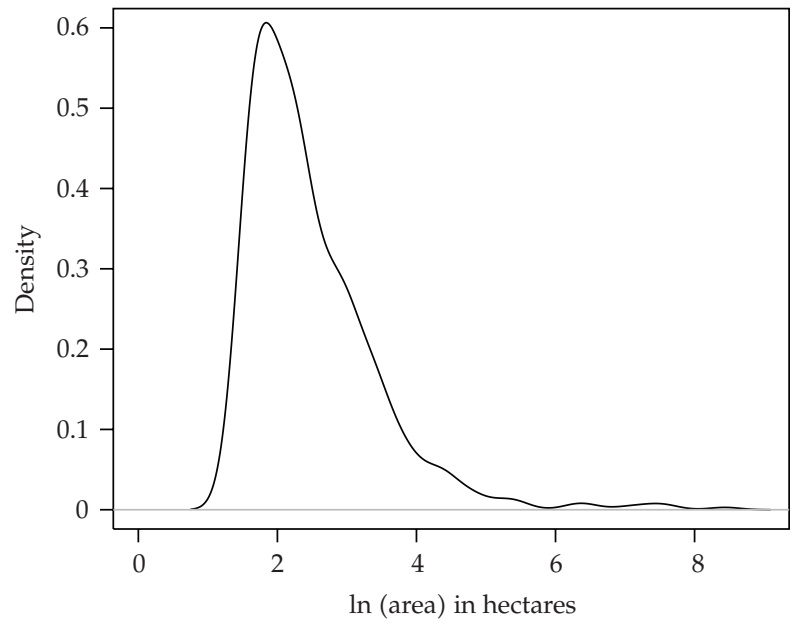

Figure 3: Estimated density of natural log-transformed fire sizes of historic escaped fires (1980-2007).

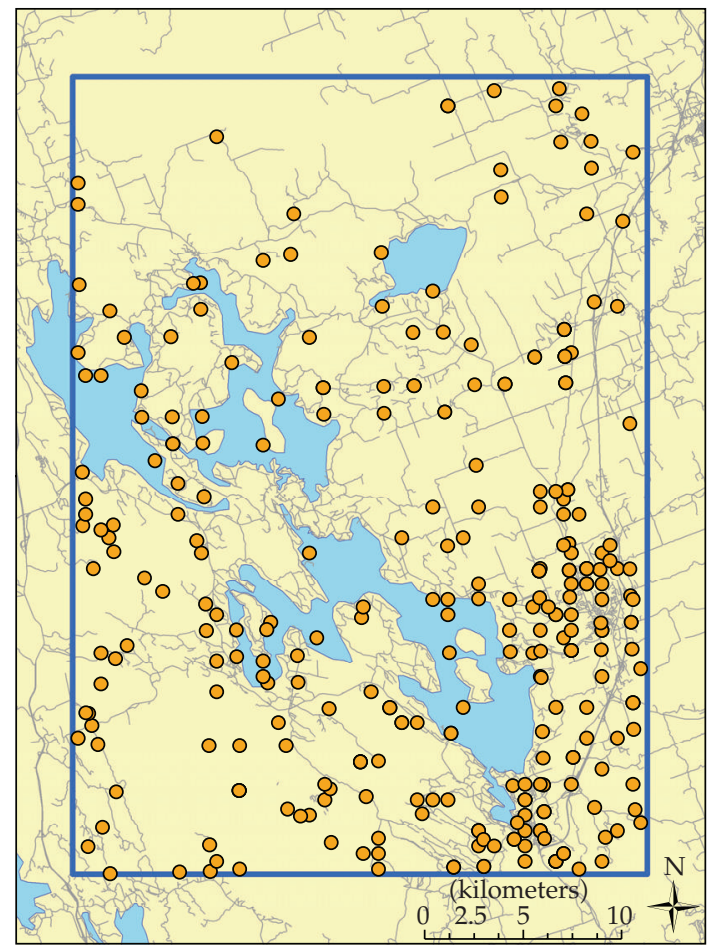

Figure 4: Map of human ignition locations in study area (1980-2007).

We have explored our data set with a simple model from within this family of models:

$$
\operatorname{logit}\left(p_{s}\right)=f\left(s_{1}, s_{2}\right)+\log \left(\frac{1}{\pi_{s}}\right)
$$




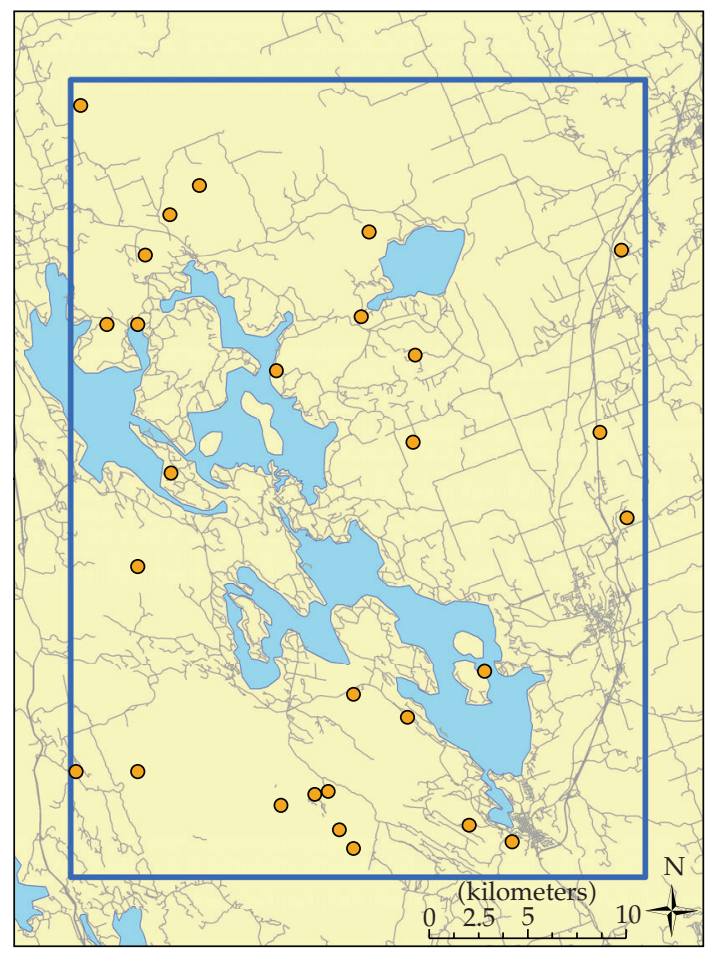

Figure 5: Map of lightning ignition locations in study area (1980-2007).

where $p_{s}=$ probability of ignition at site $s$ and $f\left(s_{1}, s_{2}\right)$ is a penalized tensor product spline smoother using the cubic B-spline basis in each dimension [see 19, Chapter 4]. We have taken

$$
\pi_{s}= \begin{cases}0.01 & \text { if sites do not contain an ignition (i.e., a “0”) } \\ 1 & \text { if sites contain an ignition (i.e., a “ } 1 \text { "). }\end{cases}
$$

We chose this value for $\pi_{s}$ in order to have a manageable data set which has sufficient covariate information for inference. The resulting ignition risk map is shown in Figure 6. We note that there is a relatively high risk of ignition in the southeast region. This is the region closest to the town of Gravenhurst. The rest of the region is less heavily populated, and thus less likely to be subject to human-caused ignitions.

\subsection{Simple Burn Probability Map}

We also used the above modelling approach to assess the probability of burning by applying the same methodology but instead of assigning a value of 1 to a pixel that had an ignition, we assign a value of 1 to pixels that have burned, either directly by an ignition or spread from an ignition point. Unfortunately, actual final fire shape was not available in the database, so we made a crude approximation based on the observed final burned areas. The resulting burn probability map is pictured in Figure 7. Notice the decreased fire risk near the town and the increase in fire risk to the north and to the west. Because of the proximity to town, it may be that the ignited fires in the southeast may be suppressed relatively quickly, leading to smaller burned area. This phenomenon has been well documented (e.g., [2]). 


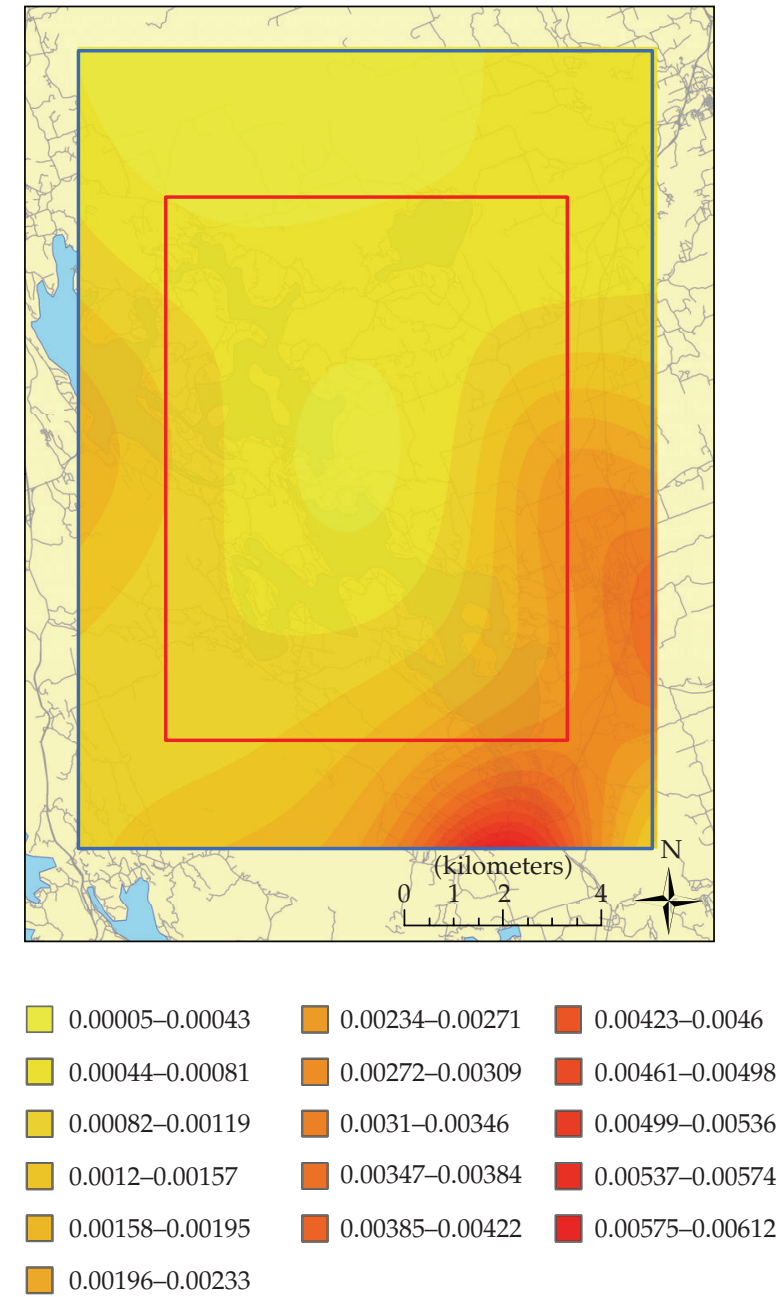

Figure 6: Model of ignition risk using generalized additive models with historic ignition data.

In addition to the loss of accuracy due to incorrect fire shape, the presence of relatively large lakes in the study area causes some difficulties for the smoother; essentially, boundarylike effects are introduced into the interior of the region. Furthermore, vegetation type and presence of other nonfuel fire barriers is not accounted for in this model.

For these reasons, we are motivated to consider a different modelling approach which is based partially on a physical model for wildfire growth and which incorporates fuel and fuel breaks. However, this map, based on historic records, can serve as a partial check on the reasonableness of the model we will propose next.

\section{Burn Probability Modelling Using a Fire Growth Model}

\subsection{The Prometheus Fire Growth Model}

Another method of forest fire risk assessment is based on computer simulation of fires, taking account of fuel information and local weather patterns. To model fire growth, we will employ the Prometheus Fire Growth Model [4]. 


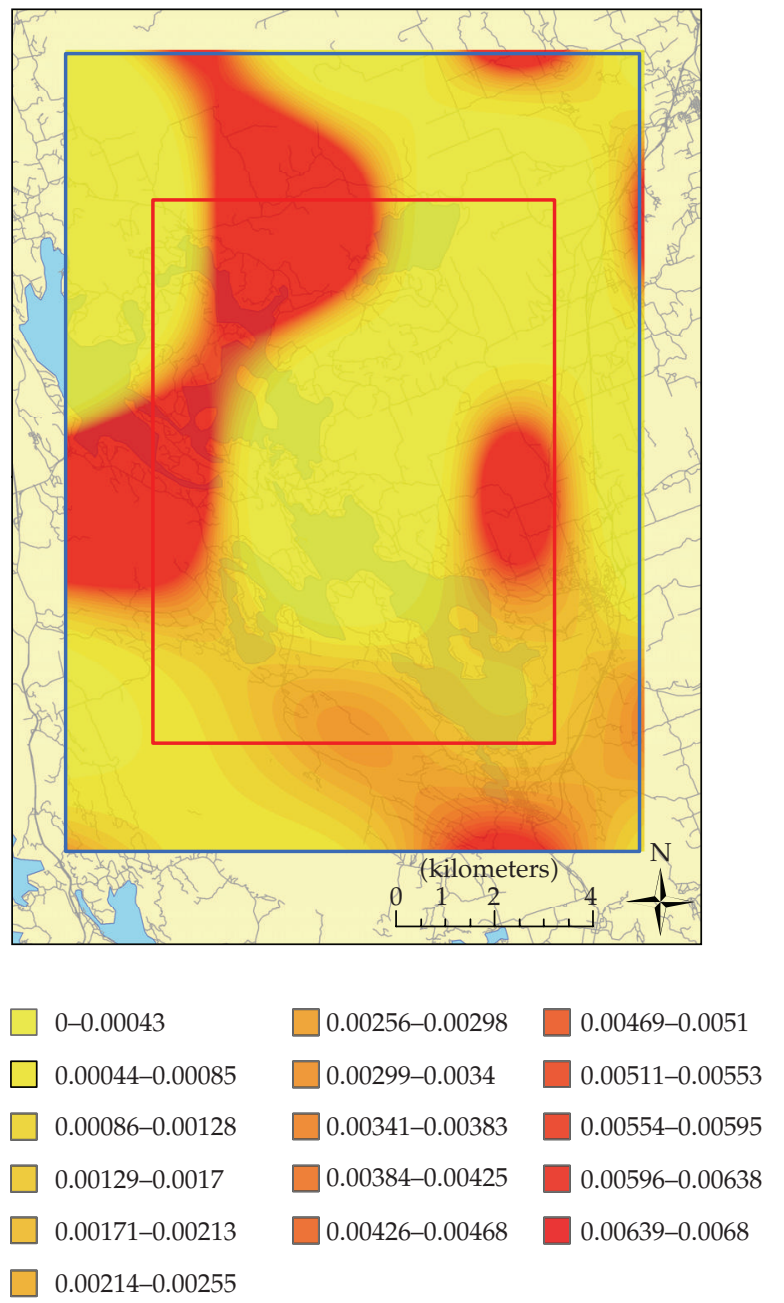

Figure 7: A simple burn probability map using generalized additive models with historic ignition data.

The evolution of a fire front simulated by Prometheus relies on the theory developed by Huygens for wave propagation: each point of a fire front at a given time acts as an ignition point for a small fire which grows in the shape of an ellipse based at that point. The size and shape of each ellipse depend on fuel composition information, weather, and various fire growth parameters as well as the time duration. The envelope containing all of the ellipses is taken to be the fire perimeter at the next time step (Figure 8).

In the absence of topographic variation, the orientation of each ellipse is aligned with the direction of the wind. The shapes of the ellipses at each time step are calculated from empirical models based on the Canadian Fire Behaviour Prediction (FBP) system which is described in the next subsection. The length of each ellipse is related to a local estimate of the forward rate of spread plus an analogous estimate of the back rate of spread, while the width of an ellipse is related to a local estimate of the flank rate of spread. These local rates of spread are, in turn, inferred from the empirical FBP models which relate spread rate to wind speed, fuel moisture, and fuel type. The measurements required for this calculation are based 
on local estimates of the weather conditions which have been extrapolated from the nearest reliable weather station. Diurnal changes in fuel moisture (as it is affected by temperature and relative humidity) and wind speed are also incorporated into the model.

\subsection{Canadian Fire Behaviour Prediction System and Fire Weather Index System}

In Canada, forest fire danger is assessed via the Canadian Forest Fire Danger Rating System (CFFDRS). As described by Natural Resources Canada [7], the current form of this system has been in development since 1968. The structure of the CFFDRS is modular and currently consists of four subsystems. Two of these subsystems are of interest in our study: the Canadian Fire Weather Index (FWI) System and the Canadian Forest Fire Behaviour Prediction (FBP) System, both of which are fully documented and are used operationally across Canada.

Many parts of the CFFDRS rely on information obtained using the FWI System. This system is comprised of six components which summarize aspects of the relative fire danger at its midafternoon peak [8]. All calculations are based on locally observed weather readings recorded at local noon: temperature, relative humidity, wind speed (usually a 10-minute average), and rainfall (over the last 24 hours). Three fuel moisture codes are calculated, each representing the dryness in a different layer of the forest floor. Three fire behaviour indices, estimating the risk of fire spread, the fuel available for combustion, and the potential intensity of a fire, are also calculated. For a recent exposition on the CFFDRS, see the account by Wotton [9] which is a review designed for modellers who require an understanding of this system and how it is to be interpreted.

The FWI System is used to estimate forest fire potential. Its outputs are unitless indicators of aspects of fire potential and are used for guiding fire managers in their decisions about resource movements, presuppression planning, and so forth. However, this is only a part of fire management. There is also the need, once fires have begun, to estimate characteristics of fire behaviour at a point on the landscape; this is done with the FBP System.

Given inputs that fall into one of five categories-fuels, weather, topography, foliar moisture content, and type and duration of prediction-the FBP System can be used to estimate fire behaviour quantitatively [10]. The FBP System calculations yield four primary and eleven secondary outputs as fire behaviour indices. It gives estimates which can be used as the basis for predictions.

The primary outputs are Rate of Spread, Fuel Consumption (as either the surface or crown consumption, or total), Head Fire Intensity, and a fire description code (crown fraction burned and fire type). The secondary outputs are Flank and Back Fire Rate of Spread; Flank and Back Fire Intensity; Head, Flank, and Back Fire Spread Distances; Elliptical Fire Area; Fire Perimeter; Rate of Perimeter Growth; and Length-to-Breadth Ratio. The primary outputs are based on a fire intensity equation and the secondary outputs are determined by assuming elliptical fire growth. All underlying models and calculations are based on an extensive 30year field experimental burning program and are fully documented [10].

\subsection{Burn-P3 Simulation Model}

A burn risk probability map can be generated using the Burn-P3 simulation model software developed by Marc Parisien of the Canadian Forest Service [5]. P3 stands for Probability, Prediction, and Planning. Burn-P3 runs repeated simulations of the Prometheus Fire Growth 


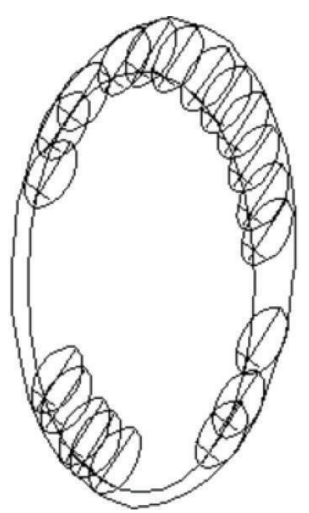

(a)

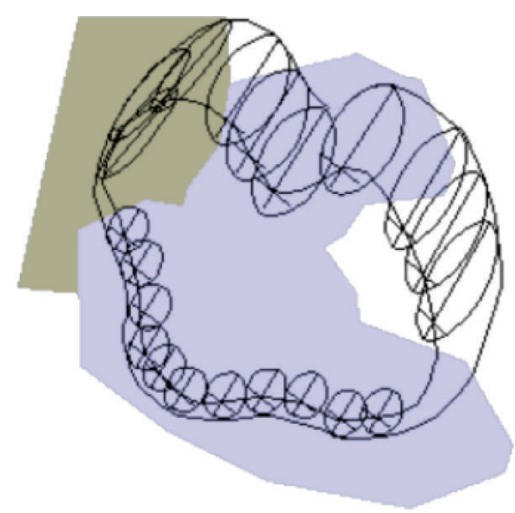

(b)

Figure 8: Illustration of fire perimeter growth under uniform burning conditions for homogenous fuels (a) and nonhomogenous fuels (b) [11].

Model, under different weather scenarios, to give estimates of the probability distribution of locations being burned during a single fire season.

In each iteration of a Burn-P3 simulation, a pseudorandom number is generated and used to sample a number from the empirical distribution of the annual number of escaped fires in the region. This empirical distribution is based on historic data. This number represents the number of simulated fires for one realization of one fire season.

For each of these fires, a random cause, season, and ignition location combination is selected from an ignition table. Burn-P3 creates an ignition table by combining ignition grids for each cause/season combination. Ignition grids partition the study area into coarse cells and represent the relative likelihood of a fire occurrence of an ignition in each cell. This spatial distribution can be empirically based on historic ignition patterns or it can be a uniform distribution, for example. The probability of selecting a certain row in the ignition table is proportional to the ignition probability of that particular cell specified in the matching ignition grid.

The duration of each simulated fire is also randomly drawn from an empirical fire duration distribution based on historic data. Given the location and fuel conditions, the Prometheus program is then used to simulate the growth of each fire individually given a random weather stream consisting of conditions conducive to fire growth from the appropriate season. All simulated fires in a single iteration are collectively used as an independent realization of a fire season.

Repeatedly simulating such fire seasons allows for construction of a burn probability map. Specifically, dividing the number of times each cell in the rasterized map of the study region has been burned by the number of simulations run gives an estimate of the probability that the particular cell will burn in a single fire season. See Figure 9 for a step-by-step illustration of this process.

The version of Burn-P3 used in this paper is not programmed to handle vectorized fuel breaks, that is, features in the landscape which tend to prevent fire from spreading. All fuel breaks such as roads are rasterized in Burn-P3 which sometimes leads to anomalous behaviour where a simulated fire passes between grid cells connected only at a single vertex. By using a small grid cell size, we can avoid this problem. 


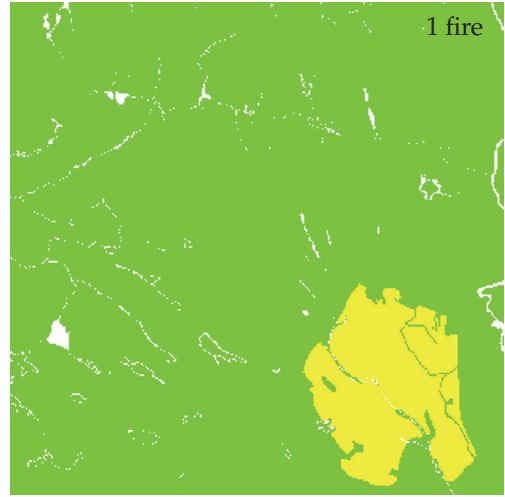

(a)

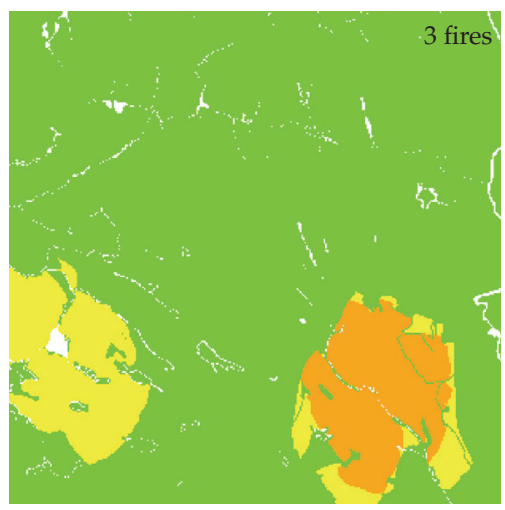

(c)

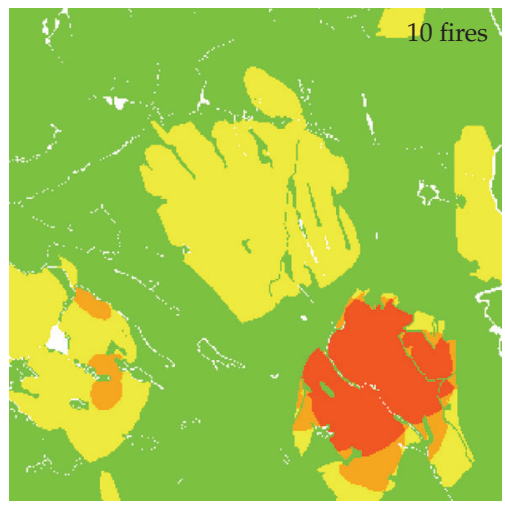

(e)

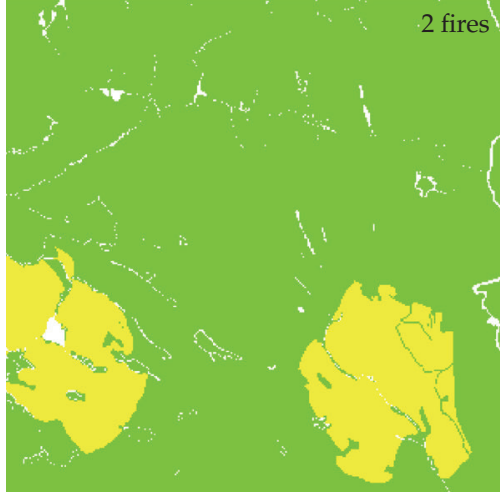

(b)

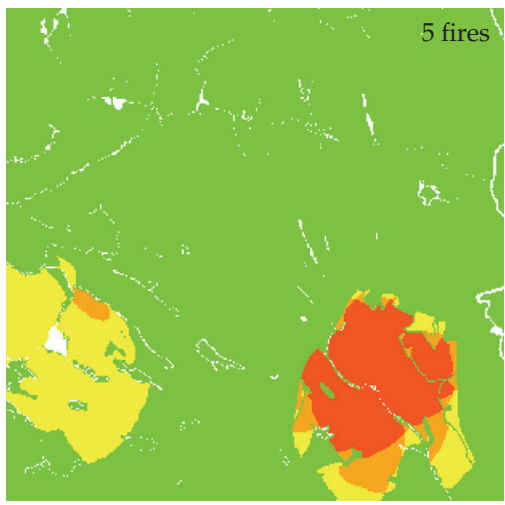

(d)

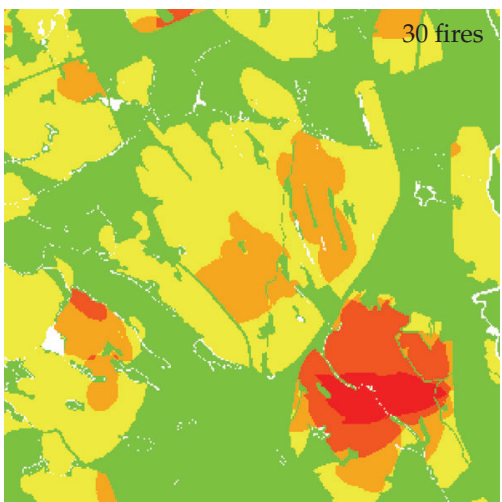

(f)

Figure 9: Step-by-step illustration of 30 iterations of the Burn-P3 simulation model. Darker colours indicate areas that have been burned more often. Green areas are unburned fuels. White areas represent nonfuel. (a) The yellow patch represents a single fire. (b) The two yellow patches represent two fires occurring in two different years. (c) Yellow patches denote areas burned by one of 3 fires occurring in different years. The orange patch represents an overlap of 2 of these fires. (d) The red patch represents an area burned by fires in 3 or more different years. 

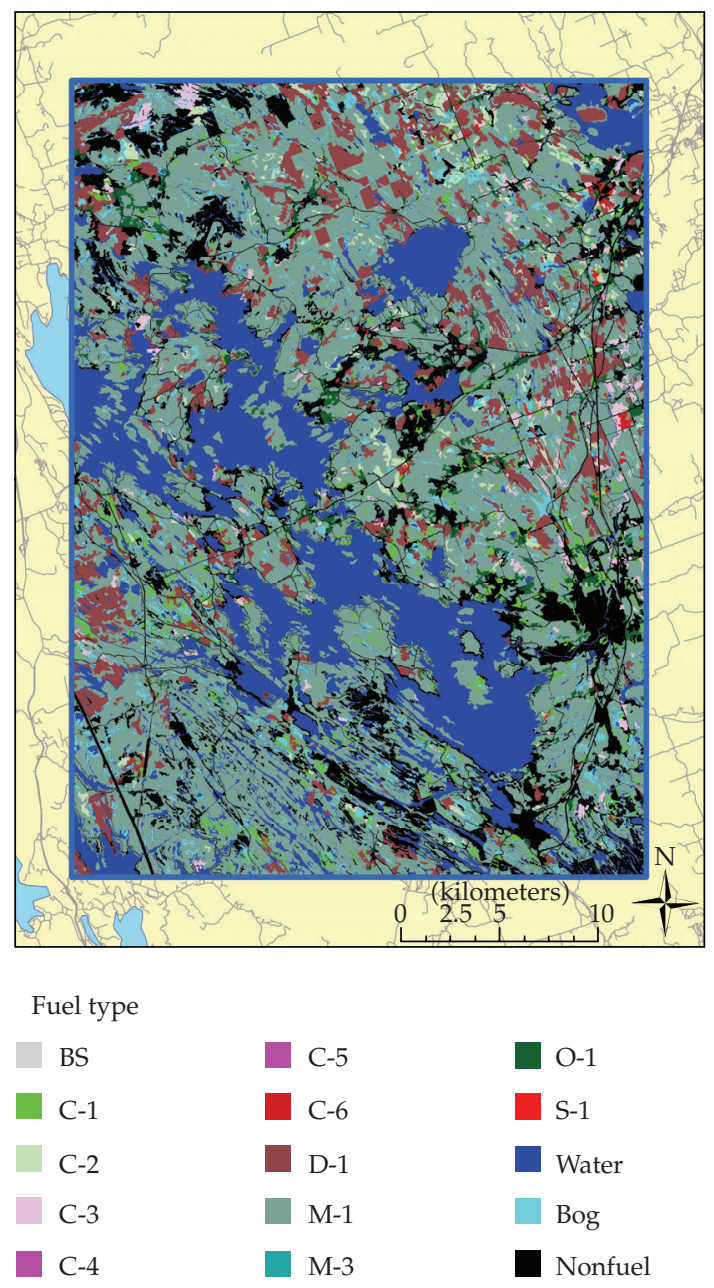

Figure 10: Corrected vector fuel map.

\subsection{Inputs}

\subsubsection{Fuel Map}

The FBP System classifies vegetation into 16 distinct fuel types (Table 1), that can further be grouped into the five categories: coniferous, deciduous, mixed wood, slash, and open [10]. A map of the fuel types in the District of Muskoka was obtained from the Ontario Ministry of Natural Resources. The fuel map was created manually from aerial photography in 1994. Fieldwork was conducted over the course of 7 days to verify and correct a subsample of the fuel map which appears in Figure 10.

\subsubsection{Verification in the Field}

Regardless of the accuracy of the fuel map at the time of its creation, fuel types and extents change over time due to land use changes, urban expansion, and natural causes such as forest succession. For example, in the study area, a large area of fuel mapped as C-6 (Conifer 
Table 1: Fire Behavior Prediction System fuel types [10].

\begin{tabular}{cc}
\hline Group/Identifier & Descriptive name \\
\hline Coniferous & \\
C-1 & Spruce-lichen woodland \\
C-2 & Boreal spruce \\
C-3 & Mature jack or lodgepole pine \\
C-4 & Immature jack or lodgepole pine \\
C-5 & Red and white pine \\
C-6 & Conifer plantation \\
C-7 & Ponderosa pine-Douglas-fire \\
\hline Deciduous & \\
D-1 & Leafless aspen \\
\hline Mixedwood & \\
M-1 & Boreal mixedwood-leafless \\
M-2 & Boreal mixedwood-green \\
M-3 & Dead balsam fir mixedwood-leafless \\
M-4 & Dead balsam fir mixedwood-green \\
\hline Slash & \\
S-1 & Jack or lodgepole pine slash \\
S-2 & White spruce-balsam slash \\
S-3 & Coastal cedar-hemlock-Douglas-fir slash \\
\hline Open & \\
O-1 & \\
\hline
\end{tabular}

Plantation) was found to be harvested and hence, was reclassified (Figure 11). Not all areas were accessible by public roads and thus could not be verified by fieldwork. Consequently, satellite imagery was used to further supplement our fieldwork to help confirm such areas.

To get an estimate of the accuracy of the fuel map, multistage cluster sampling procedure was carried out in the field. First, 20 roads were selected at random with probability proportional to the length of the road (Figure 12). For each of these roads, observations were taken at the beginning, the end, and at various points along the road. The number of observations taken was randomly generated from a Poisson distribution with rate equal to the length of the road in kilometers (Table 2). The exact locations of these observations were randomly selected from a uniform distribution from the beginning to the end of the road.

At each observation location, the width of the road (including shoulder) was measured and recorded. One person without prior knowledge of the given fuel classification gave his best assessment of fuel classification of the fuels on either side of the road, making sure to look beyond the immediate vegetation at the tree line. Both the assessed fuel classification and original fuel classification were recorded.

Three of these selected roads were privately owned or not maintained enough to be traversable; these were not included in the sample. A summary of results is given in Table 3. The subjective nature of fuel classification can be seen in the $81.1 \%$ misclassification rate 


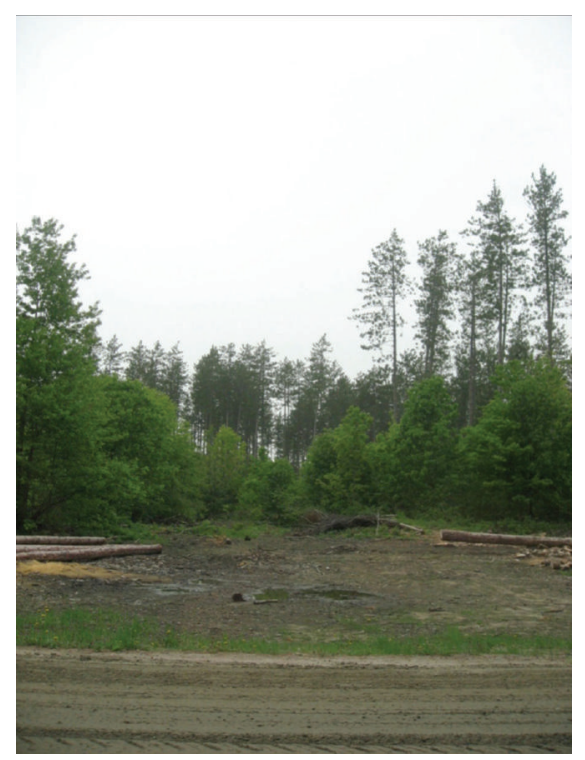

Figure 11: Area mapped as C-6 that has since been harvested and required reclassification.

assuming no tolerance for classification error. However, not all differences in observations can be considered practically important. For example, an area assessed as 10\% mixed wood originally classified as $20 \%$ mixed wood was not updated because the resulting change in fire behaviour is very slight; the rate of spread changes marginally and the direction of spread would not be affected at all. On the other hand, if a nonfuel was incorrectly classified as some form of fuel in the original map, the correction was made because the difference in fire behaviour could be substantial. Using this criterion, the misclassification rate was found to be to $22.7 \%$ in our sample: most of the fuel types were close to what we assessed them to be.

\subsubsection{Unmapped Private Properties}

The main properties of interest are those located along the waterfront because they represent the highest concentration of values at risk. Unfortunately, on the fuel map obtained from the Ontario Ministry of Natural Resources, such areas are almost always mapped as nonfuels because this is a private land not included in the Forest Resource Inventories on which the fuels classification is based. From what was observed in the field, most of these properties are located very close to fuels and could in fact be treated as a separately defined fuel type (Figure 13). The fuel types in these properties are almost always similar to what is located on the opposite side of the road further inland. For the purpose of this paper, we will assume that forest stands are continuous across roads into waterfront properties mapped as nonfuel.

Some properties have isolated buildings separated from surrounding fields (e.g., by a well-kept lawn or driveway). Although these buildings are unlikely to be damaged directly by a wildfire, they are still at risk to ignitions caused by spotting. Fire spotting is the situation where firebrands are transported long distances by the wind to start new fires. On waterfront properties, isolated buildings are not common. Thus, we further assume that all such properties have the same fuel type as the surrounding area. 


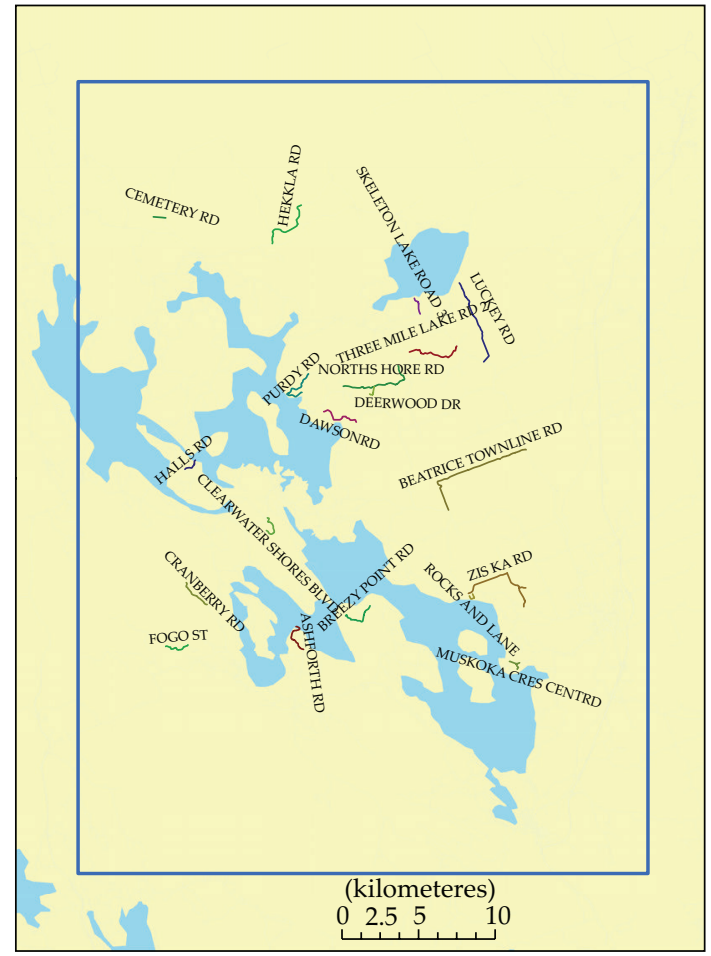

Figure 12: Map of the 20 randomly selected roads to be sampled.

Table 2: Names of the 20 randomly selected roads to be sampled, the number of observations taken on each road, and the location of each observation.

\begin{tabular}{lcc}
\hline Name of Road & Number of observations & Locations along road $(\mathrm{km})$ \\
\hline Cemetery Road & 3 & $0,0.5,0.8$ \\
Hekkla Road & 5 & $0,1.0,2.3,2.9,4.3$ \\
Deerwood Drive & 2 & $0,0.7$ \\
Purdy Road & 4 & $0,0.1,1.4,2.4$ \\
North Shore Road & 8 & $0,0.4,0.6,3.0,3.7,3.9,4.9,5.3$ \\
Skeleton Lake Road 3 & 2 & $0,1.2$ \\
Three Mile Lake Road & 3 & $0,2.5,3.3$ \\
Walkers Road* & 10 & $0,1.9,2.7,3.6,3.7,4.4,5.1,5.5,5.6,6.5$ \\
Luckey Road* & 7 & $0,1.0,1.4,2.4,2.5,3.1,4.0$ \\
Clearwater Shores Blvd & 2 & $0,1.5$ \\
Halls Road & 2 & $0,0.8$ \\
Dawson Road & 8 & $0,0.1,1.7,2.0,2.1,2.5,2.6,2.9$ \\
Beatrice Townline & 9 & $0,1.0,2.1,5.2,7.1,7.5,7.6,8.0,8.4$ \\
Cranberry Road & 4 & $0,0.6,1.9,2.1$ \\
Fogo Street & 3 & $0,1.3,1.8$ \\
Breezy Point Road & 5 & $0,0.5,0.9,1.3,2.6$ \\
Ashworth Road & 4 & $0,0.3,1.2,1.7$ \\
Ziska Road & 8 & $0,0.9,1.9,3.3,4.6,4.9,5.2,5.3$ \\
Rock Sand Lane & 3 & $0.2,0.7$ \\
Muskoka Crescent Road & 2 & $0,6.1$ \\
\hline
\end{tabular}

*Inaccessible roads. 
Table 3: Summary of fuel map accuracy sampling procedure.

\begin{tabular}{lc}
\hline Tolerance Margin & $\%$ Misclassified \\
\hline Zero tolerance & $81.1 \%$ \\
Little practical difference & $22.7 \%$ \\
\hline
\end{tabular}

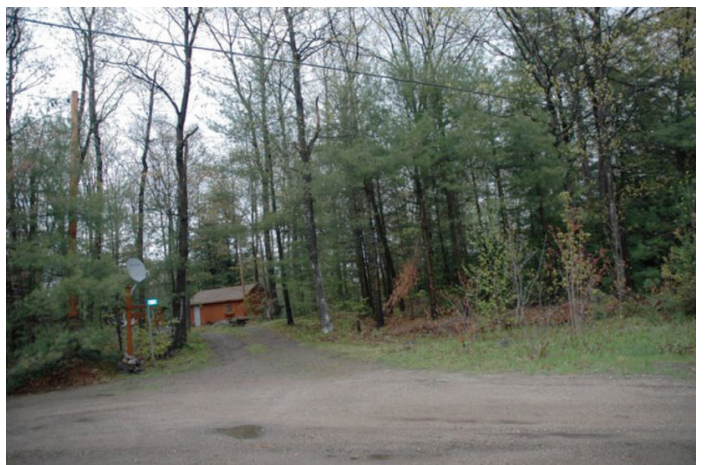

Figure 13: A structure embedded in a region of continuous fuel.

\subsubsection{Fuel Breaks}

As we have seen, fuel breaks are wide regions of what are essentially nonfuels that have the potential to prevent a fire from spreading across. The most common fuel breaks are roads, water bodies, and power lines.

The fuel map classifies major roads as nonfuels. Smaller private roads have not been included on the map. In some cases, they are located within larger private property regions mapped as nonfuel. We traced such roads from road data provided by the National Road Network. These data contain the locations of almost all roads as well as the number of lanes per road. We took a random sample of roads of varying numbers of lanes to measure their effective widths. Not only are lane widths not uniform on smaller roads, the size of the shoulder and distance to the tree line are highly variable. We used an average of sampled road widths for roads for which the widths are unknown or cannot be reasonably estimated.

Bodies of water such as lakes and rivers are clearly and accurately identified on the fuel map. However, bogs and swamps are problematic, since they are occasionally classified as water. Although a sufficiently dry bog could potentially become a fuel source in the heat of summer, the current fire growth model does not account for such a phenomenon.

Power lines introduce a further difficulty, since they are not identified on the fuel map. When power lines are built in a forested area, a path is cleared and growth underneath the line is regularly maintained. The width of this clearing and the amount of growth directly underneath the power line vary depending on how regular such maintenance occurs. Without a map of the smaller power lines, power lines are assumed to be negligible as fuel breaks.

\subsubsection{Rasterization}

The corrected vector fuel map must be converted to a raster map before it can be used by the Burn-P3 program. In doing so, detail at resolutions smaller than the grid cell resolution of the raster fuel map may be lost. However, refining the resolution of the raster fuel map 

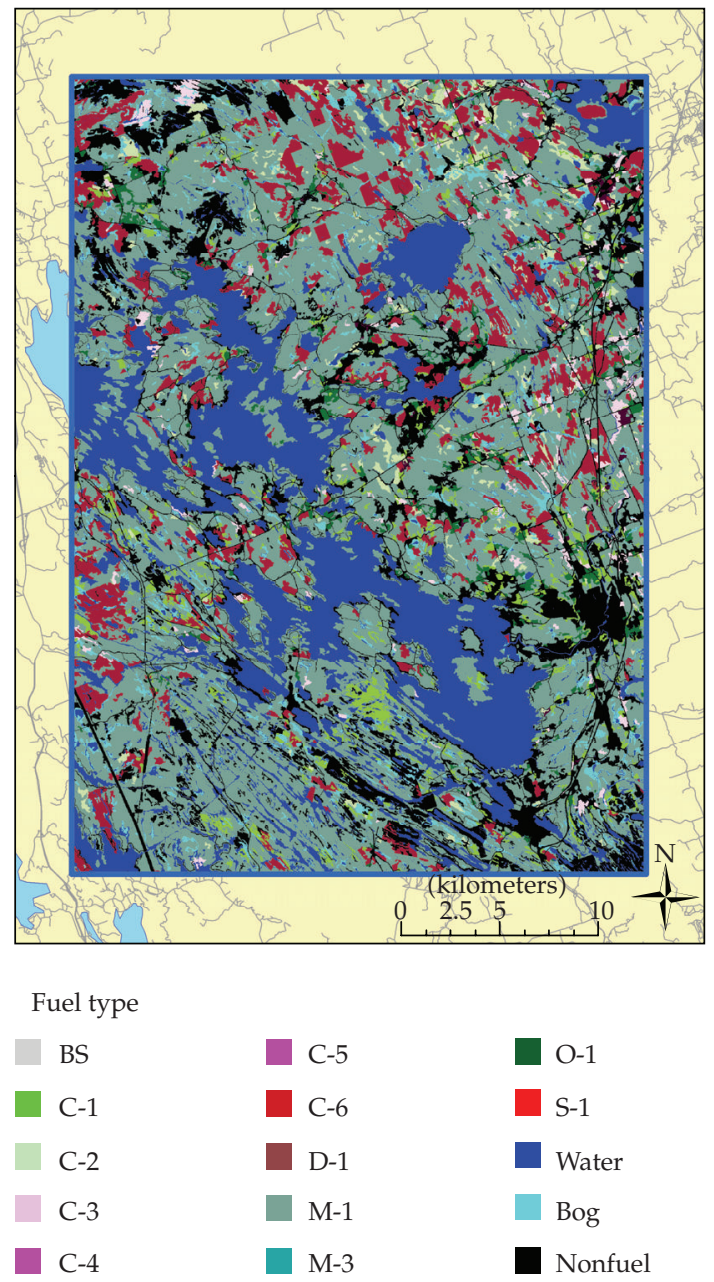

Figure 14: Rasterized fuel map at $25 \mathrm{~m}$ resolution.

directly increases computation time. In this assessment, a $25 \mathrm{~m}$ resolution (Figure 14) was used. A coarser resolution of $150 \mathrm{~m}$ was also tested, but we have not included the results of this rasterization, because important features such as fuel breaks were not respected.

\subsubsection{Historic Weather}

We obtained weather data from surrounding weather stations. The most complete weather record also happens to be the station closest to the study region so only weather data from this station was used in our analysis. This weather record begins with the 1980 fire season.

Only the extreme weather days are used for input to the Burn-P3 program. These days, in which there is potential for substantial fire growth, are referred to as spread event days. Days when the initial spread index (ISI) is less than 7.5 are considered to be nonextreme and are deleted from the weather stream. The resulting data set consists of 232 cases, each representing to a single day. Given the large number of simulations to be run, these weather conditions are sampled frequently. 


\subsubsection{Seasons and Causes}

To properly simulate the growth of fires for an entire year, fires need to be classified by cause and by season in which they occur.

In regions with a mixture of deciduous and coniferous vegetation, there are often two distinct fire subseasons each year, the first immediately following snowmelt, and the second in summer. The spring fire subseason is a period of increased fire risk because leaves have not appeared on the deciduous trees leading to drier surface conditions. Since there is limited lightning activity during this period, ignitions are primarily due to people.

After the leaves appear, there is often a brief interval with few fires. Fire occurrence increases with temperature increase and as lightning activity increases. Thus, during the summer fire subseason, ignitions are due to people and lightning. This results in different spatial ignition patterns depending on time of year.

Operationally, early to mid June is typically taken as the transition date between the spring and summer seasons when classifying fires. However, this date is inferred from observations taken in the northern boreal forest. The District of Muskoka is further south and experiences a slightly warmer climate. Consequently, it is reasonable to assume that the actual transition date occurs approximately a week earlier. Looking at the distribution of human caused fires (Figure 15), we can see a dip on June 11th in human caused ignitions which is used as an estimate of the transition date and is highlighted with a vertical line in the figure.

All fire ignitions can be classified into either human- or lightning-caused fires. Humancaused fires can be further subdivided into eight specific causes: recreational, residential, railway, forestry industrial, nonforestry industrial, incendiary, miscellaneous, and unknown. Each of these causes is associated more strongly with either the spring or summer season (Figure 16). Between 1996 and 2005 inclusive, across the province, there were a total of 12,974 wildfires resulting in over 1.5 million hectares burned. Of these ignitions, nearly 7,000 can be attributed to lightning.

\subsubsection{Ignition Grids}

For each season and cause combination, ignition grids were created to represent the relative likelihood of an ignition in a certain cell. To create the ignition grids for human caused fires, a grid twenty times coarser than the fuel grid was created and assigned a value of 1 . For each historic fire, the cell in which the ignition occurred had its value incremented by 1 . Lightning ignitions in the region appear to be uniformly random and so a uniform ignition grid was used for lightning-caused ignitions.

\subsubsection{Estimation of Spread Event Days}

Burn-P3 models fire growth only on spread event days. The number of spread event days is not necessarily equal to the total duration of a fire; there may be days for which a fire does not spread (either due to suppression or nonconducive weather). The fire data do not contain information on fire spread days so a best estimate is made by counting the number of days from the fire start date to the date in which the fire was reported as "held". A held fire is one that has been completely surrounded by fire line (i.e., fuel breaks constructed by suppression efforts as well as naturally occurring fuel breaks). The historic data on the distributions of spread event days per fire, as defined previously, is displayed in Figure 17. 


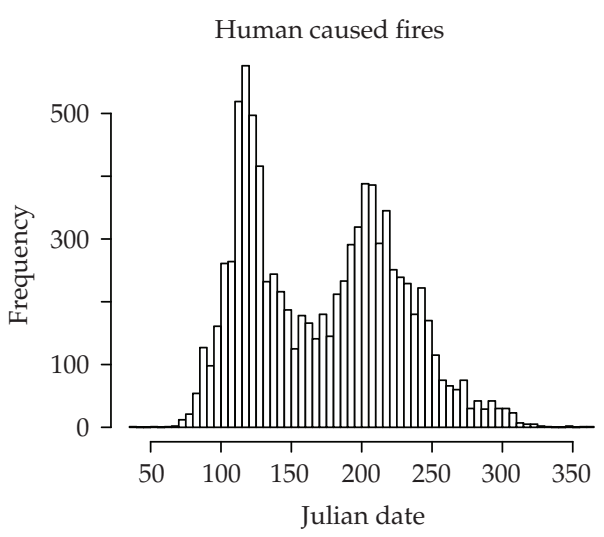

(a)

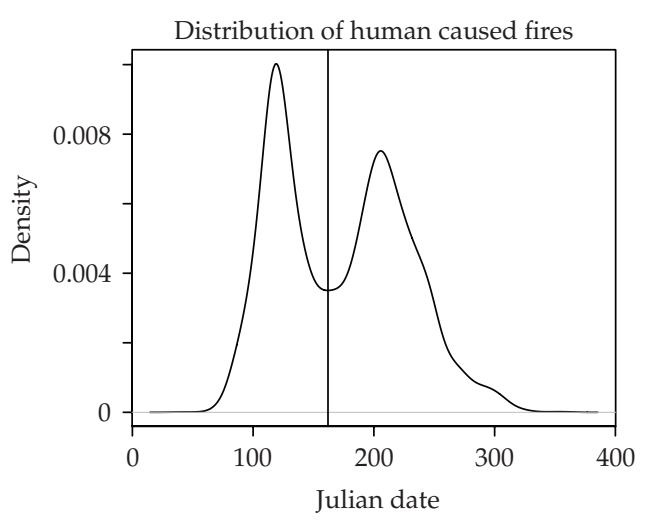

(b)

Figure 15: Distribution of human caused forest fires during the year. The vertical line indicates the minimum of the dip, corresponding to June 11 th.

The FBP System's rate of spread is based on peak burning conditions, which are assumed to occur in the late afternoon, generally specified as 1600 hours [10]. Consequently, any fire growth models based on this system are effectively simulating spread event days [12].

\section{Analysis and Results}

We will begin this section by discussing the application of the Burn-P3 simulator to the corrected fuel map when the recommended settings are used. We will then discuss the results of a sensitivity analysis in which the effects of fuel break misclassification on the burn probabilities are studied. This will provide an indication of the uncertainty induced by possible inaccuracies in the fuel map. We next compare the burn probability map obtained from Burn-P3 with the map obtained using generalized additive models, and finally compare simulated fire size distributions with the historical record; this ultimately guides us to what we believe is a more accurate burn probability map.

A uniform ignition grid for lightning caused fires is normally recommended for use in Burn-P3. For human-caused fires, the ignition grid is also uniform, but with increased probability at locations where previous ignitions occurred. The distribution of spread event days is based on historic weather data where the weather stream has been adjusted so that it only contains extreme weather, conducive to fire growth. Using these recommended settings, we obtain the burn probability map and fire size distribution as shown in the left panel of Figure 18.

In that figure, it can be seen that the fire risk is higher in the north. This result seems plausible, since there are larger forest stands in that region, and we have already conjectured on the possibility of large fires spreading into the study region from further north.

In order to assess the uncertainty induced by possible inaccuracies in the fuel map, we conducted the same simulation but with $20 \%$ of randomly selected nonfuel grid cells converted to the M-1 20\% mixed wood fuel type. By making this kind of change, we should observe the largest range of realistic fire behaviour in the study region, since much of the forest in the area is of M-1 type, and changes within this categorization have minimal effect on fire behaviour. By contrast, changes from nonfuel to any kind of of fuel can have relatively 


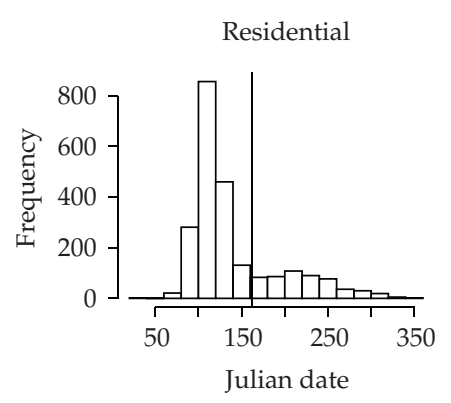

(a)

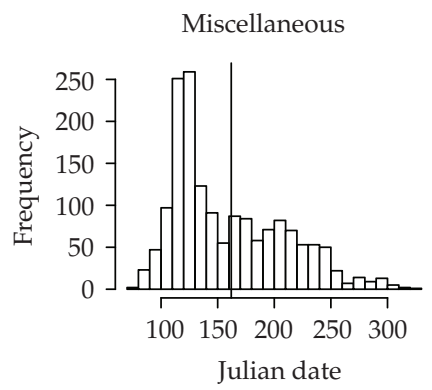

(d)

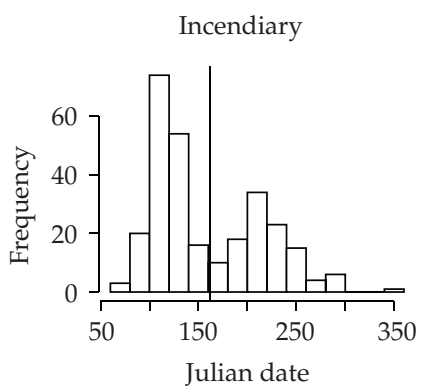

(g)

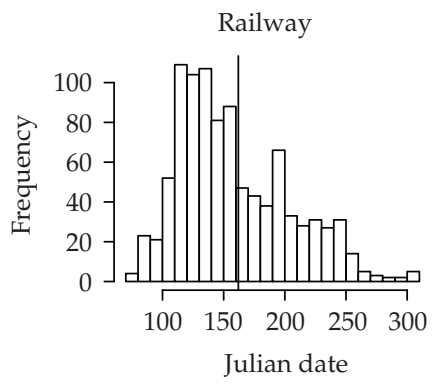

(b)

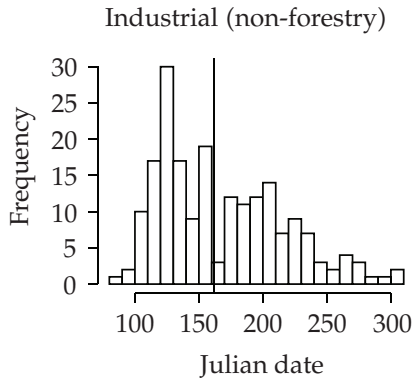

(e)

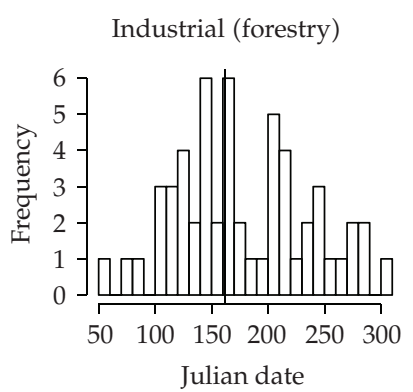

(h)

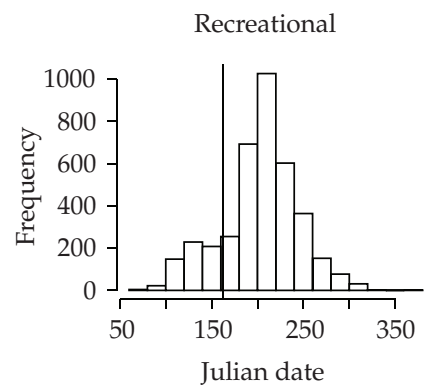

(c)

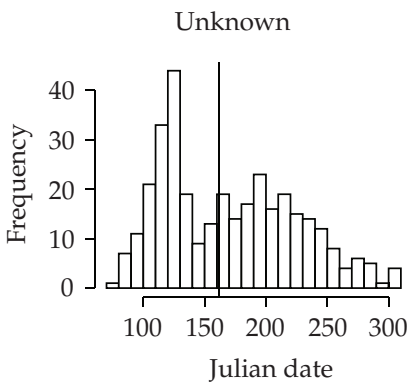

(f)

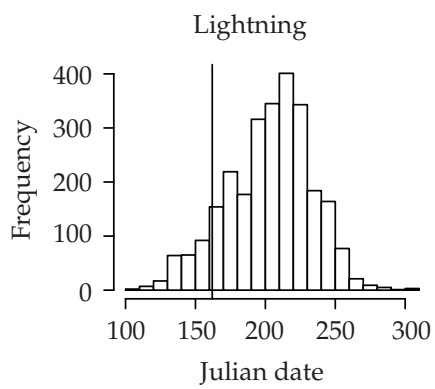

(i)

Figure 16: Histograms of forest fires during the year by cause. Vertical line indicates June 11th, the estimated transition date used to separate "spring" and "summer" subseasons.

dramatic effects on fire behaviour, since nonfuel regions often serve as fuel breaks; replacing parts of such regions with fuel allows for the possibility of a fire breach where it would not otherwise have been possible. As expected, the burn probability map (Figure 18(b)) exhibits larger regions of relatively high probability than in the original map, especially in the eastern region as well as in the north. Note that regions where the burn probability was already relatively high do not see a substantial gain in burn probability when the nonfuels are perturbed. Rather, we see somewhat more substantial increases in burn probability in those areas where the probability was much less. An additional simulation was run with only $10 \%$ of the nonfuel randomly converted to fuel; we have not shown the resulting map because of its similarity to the map in the right panel of Figure 18. We conclude that gross misclassification of fuel as nonfuel could lead to a moderate underestimate of the area at elevated risk. 


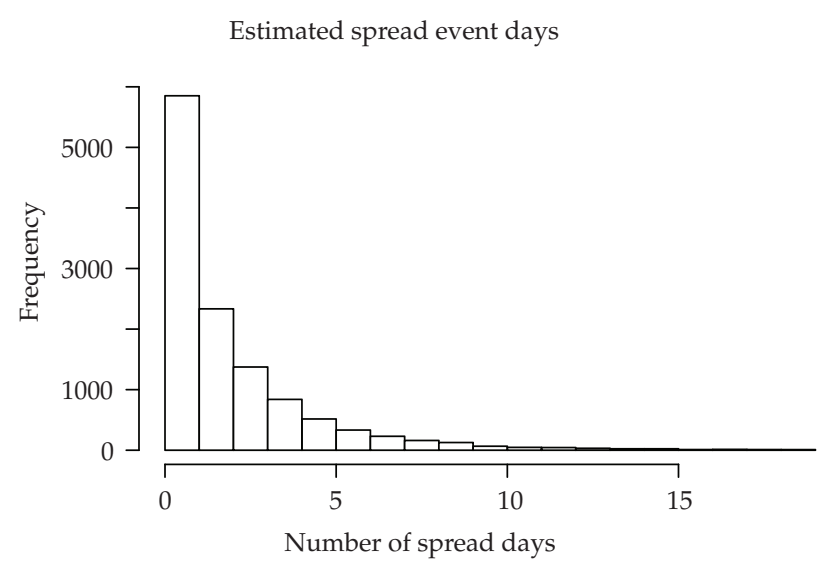

Figure 17: Histogram of estimated spread event days.

Comparing the map obtained from Burn-P3 using the corrected and unperturbed fuel map (Figure 18) with the burn probability map obtained using the generalized additive model (Figure 7), we see some similarities. Both maps exhibit elevated burn risk in the north, but the prevalence of ignitions in the southeast seems to figure more prominently in the map obtained from the generalized additive model. It should be noted that the latter map is based on accurate fire sizes but incorrect fire shapes, while the former map is based on what are possibly more realistic fire shapes, but with a fire shape and size distribution that is determined by the weather and fuels.

We can then use the historic fire size distribution as a check on the accuracy of the Burn-P3 output. Figure 19 shows the estimated density of fire sizes in the study region (solid black curve) on the natural logarithmic scale. The dashed curve represents the estimated density of the simulated log fire sizes under the recommended settings, and the dotted curve corresponds to the perturbed nonfuel simulation. Both densities fail to match that of the historic record. Modal log fire sizes are close to 2 in the historic record, while the simulations give modes exceeding 5 . Note that, in accordance with our earlier observations regarding the nonfuels, the fire sizes indeed increase when fuel breaks are removed.

In order to find a model which matches the historic record more closely, we could introduce additional fuel breaks, but we have no way of determining where they should be located without additional (substantial) fieldwork, and the earlier sensitivity study indicates that even fairly substantial errors in the fuel map will lead to only modest discrepancies in the fire size distribution. Instead, it may be more important to consider the effects due to weather. To investigate this, we have run four additional Burn-P3 simulations under different settings. The resulting burn probability maps appear in Figure 20. We now proceed to describe these simulations and their resulting fire size distributions.

First, we replaced the spread event day distribution with a point mass at 1 day. In other words, we made the assumption that even if fires in the area burn for several days, there would only be one day in which the fire would burn a nonnegligible amount. All other simulation settings remain as before. The fire size distribution for this situation is pictured in Figure 19 as the long-dashed curve, having a mode near 4. This is closer to the historic record, but still unsatisfactory. 


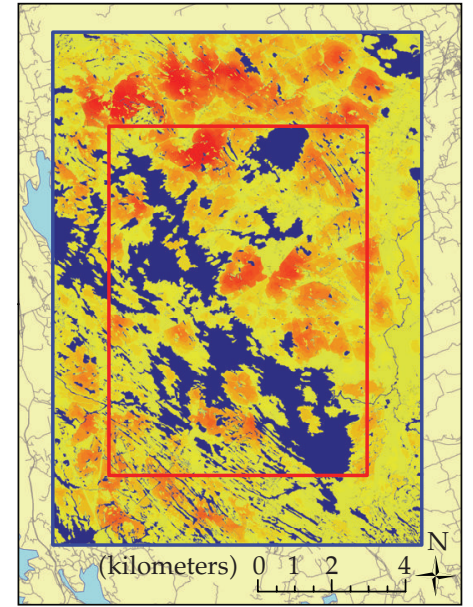

$\begin{array}{ll}0-0.000181 & \square 0.001445-0.001625 \\ 0.000182-0.000361 & \square 0.001626-0.001806 \\ 0.000362-0.000542 & \square 0.001807-0.001986 \\ 0.000543-0.000722 & \square 0.001987-0.002167 \\ 0.000723-0.000903 & \square 0.002168-0.002347 \\ 0.000904-0.001083 & \square 0.002348-0.002528 \\ 0.001084-0.001264 & \square 0.002529-0.002708 \\ 0.001265-0.001444 & \square 0.002709-0.002889\end{array}$

(a)
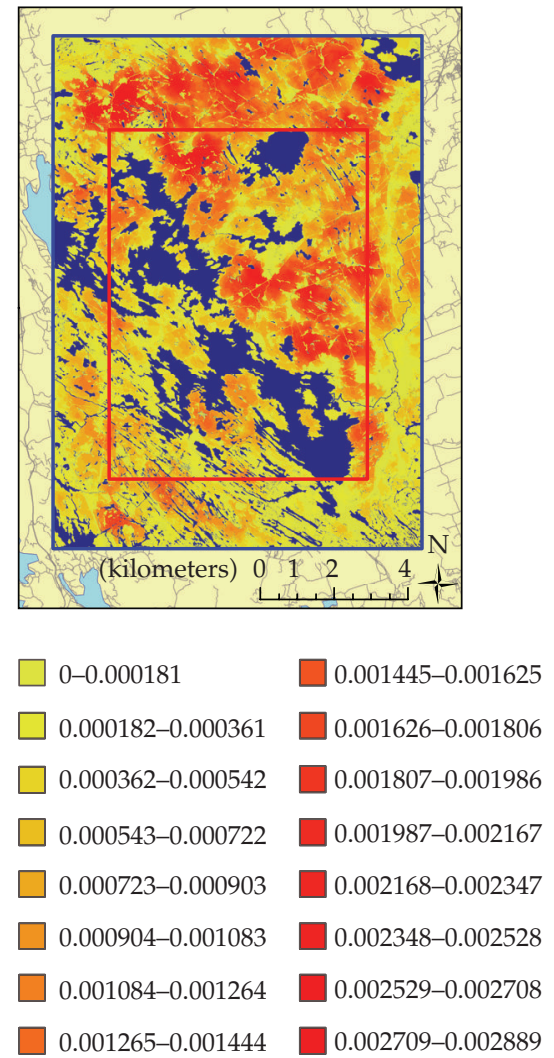

(b)

Figure 18: (a) Burn probability map of simulated fires using recommended Burn-P3 settings. (b) Burn probability map of simulated fires using recommended settings and $20 \%$ of nonfuels randomly converted to M-1 fuel type.

The next simulation made use of the entire weather record, dispensing with the notion of spread event days completely. Fire durations were sampled from historic fire duration distribution. Again, all other simulation settings were the same as before. The resulting fire size distribution is displayed in Figure 19 as the dashed-dotted curve, having a mode near 3-a substantial improvement, but still not satisfactory. The difference between this result and the earlier simulations which depend only on extreme weather calls such practice into question.

In the succeeding simulation run, the duration of the fires was reduced to a single day, again sampling from the full weather stream. The resulting density estimate is displayed in Figure 19 as the long-dashed-dotted curve, having a mode near the historic mode, although its peak is not nearly as pronounced. An additional simulation was conducted using the same settings but with an ignition grid based on the generalized additive model for ignitions obtained in Section 3.1. The resulting fire size distribution is also pictured in Figure 19 and is very similar to the result of the preceding simulation.

We conclude that the use of the full weather stream and that limiting the duration of the fires to one day give more accurate fire size distributions. Use of the uniform ignition grid is slightly less accurate than the use of the modelled grid based on historic ignitions. 


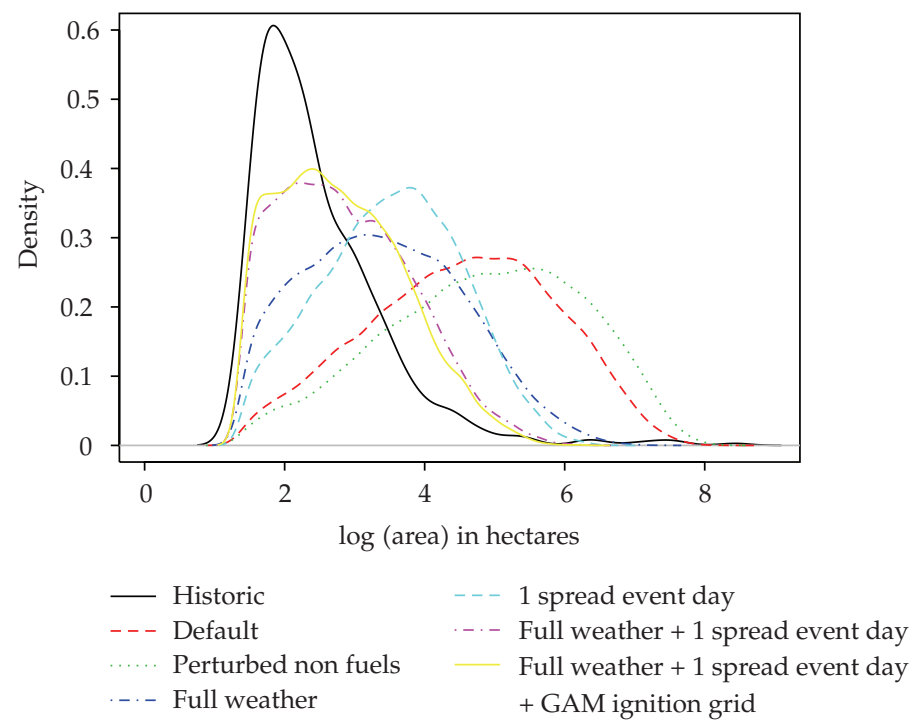

Figure 19: Estimated density functions of log-transformed simulated and observed fire sizes under various scenarios. The historic fire size density is based on data from an area encompassing the study region (19802007). The other fire curves are based on Burn-P3 simulations, using the default setting with the corrected fuel map as well as a fuel map with $20 \%$ of the nonfuel randomly selected to be changed to mixed woodtype fuel. The Full weather curve is based on a simulation using all weather data but with the same spread event day distribution as before.

\section{Discussion}

We have shown how to estimate a burn probability map which could be used by insurers to estimate expected losses due to wildfire risk in the region under study. We found that substantial perturbation of the fuel map, converting nonfuels to fuels, gives rise to moderate changes in the fire risk.

We have also used historic fire size distribution information as a check on its accuracy and found that the recommendation to use a spread event day distribution for fire duration overestimates the fire size distribution. The use of spread event days in the Burn-P3 model could be degrading the probability estimates. The spread event day distribution may be biased since it is based on the time between when a fire was first reported and when it was declared as being successfully held by suppression activities. A fire would not necessarily be spreading rapidly during this entire period.

Note that fire suppression is not accounted for directly in Burn-P3. This could account for the difference between the simulated and observed fire size distributions. By using the full weather stream and a one day fire duration, the simulated fire size distribution comes closer to matching the historic record. In fact, using the 1 day fire duration may be realistic because of suppression effects; it is unlikely that most fires are allowed to burn for more than 1 day in this region without being attacked. If allowed to burn longer, it would not be under extreme weather conditions, and such fires would not be spreading fast.

Thus, there is some justification for our approach. We note, however, that there is still a discrepancy between the simulated fire size distribution and the historic record. As we saw, fuel/nonfuel misclassification can have a modest effect on the fire size distribution estimates. It is possible that some of the small roads that are not classified as fuel breaks may in fact 


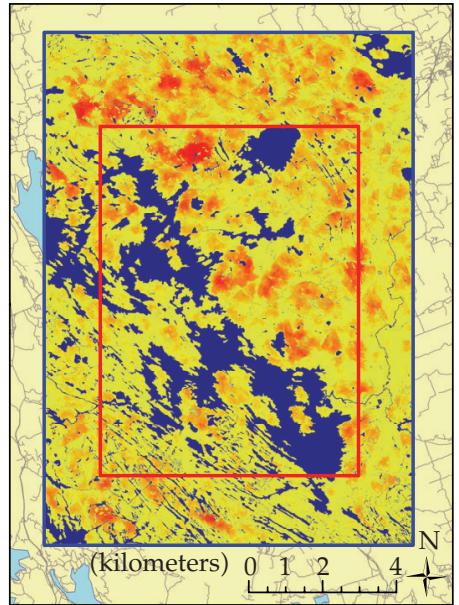

(a)

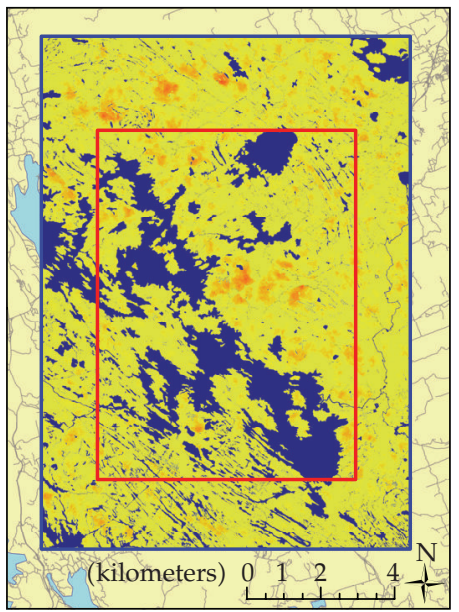

\begin{tabular}{|c|c|}
\hline $0-0.000057$ & $0.000455-0.00051$ \\
\hline $0.000058-0.000113$ & $0.000511-0.00056$ \\
\hline $0.000114-0.00017$ & $0.000568-0.00062$ \\
\hline $0.000171-0.000227$ & $0.000625-0.0006$ \\
\hline $0.000228-0.000284$ & $0.000682-0.0007$ \\
\hline $0.000285-0.00034$ & $0.000738-0.0007$ \\
\hline $0.000341-0.000397$ & $0.000795-0.0008$ \\
\hline $0.000398-0.000454$ & $0.000852-0.000$ \\
\hline
\end{tabular}

(c)

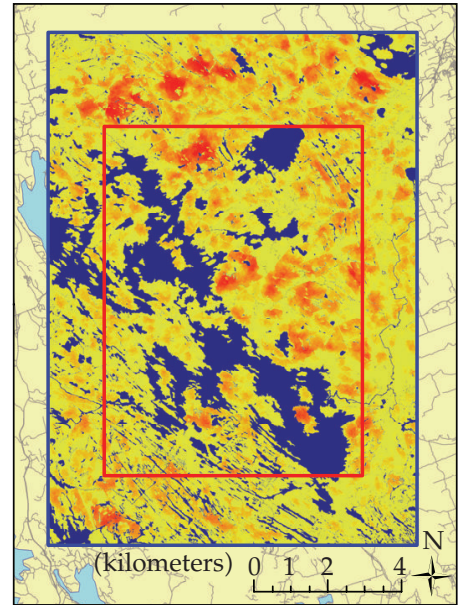

(b)

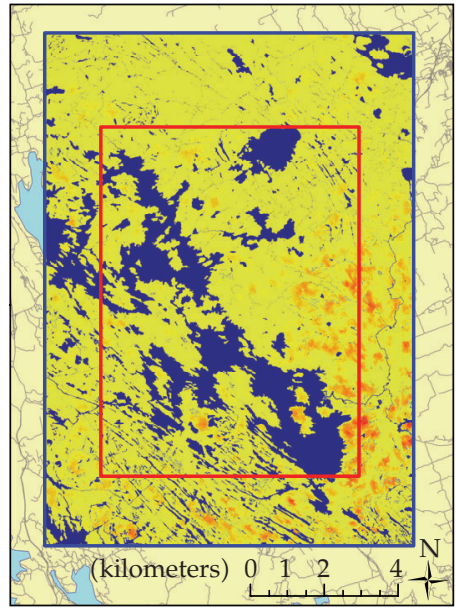

\begin{tabular}{|c|c|}
\hline $0-0.000057$ & |0.000455-0.00051 \\
\hline $0.000058-0.000113$ & $0.000511-0.000567$ \\
\hline $0.000114-0.00017$ & $0.000568-0.000624$ \\
\hline $0.000171-0.000227$ & $0.000625-0.000681$ \\
\hline $0.000228-0.000284$ & $0.000682-0.000737$ \\
\hline $0.000285-0.00034$ & $0.000738-0.000794$ \\
\hline $0.000341-0.000397$ & $0.000795-0.000851$ \\
\hline $0.000398-0.000454$ & $0.000852-0.000907$ \\
\hline
\end{tabular}

(d)

Figure 20: Burn probability maps under various simulation scenarios. (a) Using full weather stream. (b) Using one spread event day. (c) Using full weather stream and one spread event day. (d) Using full weather stream and one spread event day with ignition grid from GAM model. 
be serving as fuel breaks; this kind of error could explain the discrepancy in the fire size distributions.

Our final model indicates a relatively low burn probability across the region. Depending on the ignition grid used, the higher risk areas are either in the north (uniform grid) or to the east and southeast (historic ignition grid). The latter indicates a somewhat more serious risk for the more heavily populated area, and may be the more realistic scenario, since there is no reason to believe that the pattern of human-caused ignitions (which are largely responsible for the fires here) will change in the future without some form of intervention.

However, there are several limitations to this approach. The results obtained in this assessment need to be interpreted with some care. We should note that by using the fire size distribution as our standard for accuracy checking, we are assuming that the fuel distribution and composition is similar to how it was in the past and that the climate has not changed substantially. Future research in which this model is run under various realistic climate change scenarios will be important. Any changes in fire management in the area, either past or future, have not been factored into our estimates of fire risk.

The Prometheus Fire Growth Model has been used extensively in Canadian fire management operations. It has been found to be reasonably accurate under many circumstances, especially under peak burning conditions, which is where the FBP system is at its most accurate. Indeed, predictions from the FBP System, which forms the foundation of fire growth in the Prometheus model and consequently in Burn-P3, are used as a regular and important part of forecasting the active growth of fires and the consequent planning of fire suppression resource needs. While the FBP has limitations (see discussion below), it constitutes the best available system for predicting fire ignition and growth in the forests of Canada. Consequently, the Prometheus fire growth model as well as Burn-P3 have been used in a number of research studies in a wide variety of locations in Canada [5, 13-16].

However, the size of fires may be overstated under moderate weather conditions [12]. Since Prometheus is based on the FBP system which is, in turn, based on empirical observations, the process under which these empirical observations were collected influences model performance. Some of these observations were from controlled burns, so spread rates of wildfires in different fuel types may be quite different, at least during the acceleration phase. The reason for this is that the prescribed fires were started with a line ignition under somewhat variable weather conditions. Because of the line ignition, the estimated spread rate may be biased upwards, since point fire ignitions are more common in naturally occurring fires. Spread rates for mixed wood fuel types were not empirically developed from observed fire behaviour; instead, they were calculated as weighted averages of spread rates of coniferous and deciduous fuel types.

The Burn-P3 simulation model is also limited in that it is not programmed to handle vectorized fuel breaks so any fuel breaks smaller than the chosen cell resolution do not prevent a fire from spreading. Furthermore, inputs for Burn-P3 are based on empirical observations which makes an assumption that what will be observed in future fire seasons is similar to what has happened in the past.

\section{Acknowledgments}

Funding was provided by the Institute for Catastrophic Loss Reduction, the MITACS Accelerate internship program, and GEOIDE. The authors would also like to thank Marc Parisien for assistance in the use of the Burn-P3 simulation model, Jen Beverly and Cordy 
Tymstra for a number of helpful discussions, and the Ontario Ministry of Natural Resources for providing the fuel map of the area as well as the fire and weather data. Comments from two anonymous referees are also gratefully acknowledged.

\section{References}

[1] S. McCaffrey, "Thinking of wildfire as a natural hazard," Society and Natural Resources, vol. 17, no. 6, pp. 509-516, 2004.

[2] B. J. Stocks, J. A. Mason, J. B. Todd et al., "Large forest fires in Canada, 1959-1997," Journal of Geophysical Research D, vol. 108, no. 1, pp. 5.1-5.12, 2003.

[3] D. G. Woolford and W. J. Braun, "Convergent data sharpening for the identification and tracking of spatial temporal centers of lightning activity," Environmetrics, vol. 18, no. 5, pp. 461-479, 2007.

[4] C. Tymstra, R. W. Bryce, B. M. Wotton, and O. B. Armitage, "Development and structure of Prometheus: the Canadian wildland fire growth simulation model," Information Report NOR-X417, Natural Resources Canada, Canadian Forestry Service, Northern Forestry Centre, Edmonton, Canada, 2009.

[5] M. A. Parisien, V. G. Kafka, K. G. Hirsch, J. B. Todd, S. G. Lavoie, and P. D. Maczek, “Using the Burn-P3 simulation model to map wildfire susceptibility," Information Report NOR-X-405, Natural Resources Canada, Canadian Forest Service, Northern Forestry Centre, Edmonton, Canada, 2005.

[6] D. R. Brillinger, H. K. Preisler, and J. W. Benoit, "Risk assessment: a forest fire example," in Statistics and Science: A Festschrift for Terry Speed, D. R. Goldstein, Ed., vol. 40 of IMS Lecture Notes Monograph Series, pp. 177-196, Institute of Mathematical Statistics, Beachwood, Ohio, USA, 2003.

[7] Natural Resources Canada, "Canadian Forest Fire Danger Rating System," NRC, August 2009, http:/ / fire.nofc.cfs.nrcan.gc.ca/en/background/bi_FDR_summary_e.php .

[8] C. E. van Wagner, "Development and structure of the Canadian forest fire weather index system," Forest Technical Report 35, Canadian Forest Service, Ottawa, Canada, 1987.

[9] B. M. Wotton, "Interpreting and using outputs from the Canadian Forest Fire Danger Rating System in research applications," Environmental and Ecological Statistics, vol. 16, no. 2, pp. 107-131, 2009.

[10] Forestry Canada Fire Danger Group, "Development and structure of the Canadian forest fire behavior prediction system," Information Report ST-X-3, Forestry Canada, Science and Sustainable Development Directorate, Ottawa, Canada, 1992.

[11] FARSITE, 2008, http://www.firemodels.org/.

[12] J. J. Podur, Weather, forest vegetation, and fire suppression influences on area burned by forest fires in Ontario, Ph.D. dissertation, Graduate Department of Forestry, University of Toronto, Toronto, Canada, 2006.

[13] C. Tymstra, M. D. Flannigan, O. B. Armitage, and K. Logan, "Impact of climate change on area burned in Alberta's boreal forest," International Journal of Wildland Fire, vol. 16, no. 2, pp. 153-160, 2007.

[14] R. Suffling, A. Grant, and R. Feick, "Modeling prescribed burns to serve as regional firebreaks to allow wildfire activity in protected areas," Forest Ecology and Management, vol. 256, no. 11, pp. 1815-1824, 2008.

[15] M. A. Parisien, C. Miller, A. Ager, and M. Finney, "Use of artificial landscapes to isolate controls on burn probability," Landscape Ecology, vol. 25, no. 1, pp. 79-93, 2010.

[16] J. L. Beverly, E. P. K. Herd, and J. C. R. Conner, "Modeling fire susceptibility in west central Alberta, Canada," Forest Ecology and Management, vol. 258, no. 7, pp. 1465-1478, 2009. 


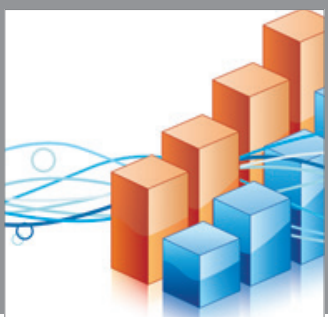

Advances in

Operations Research

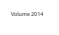

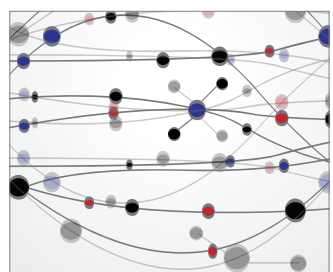

\section{The Scientific} World Journal
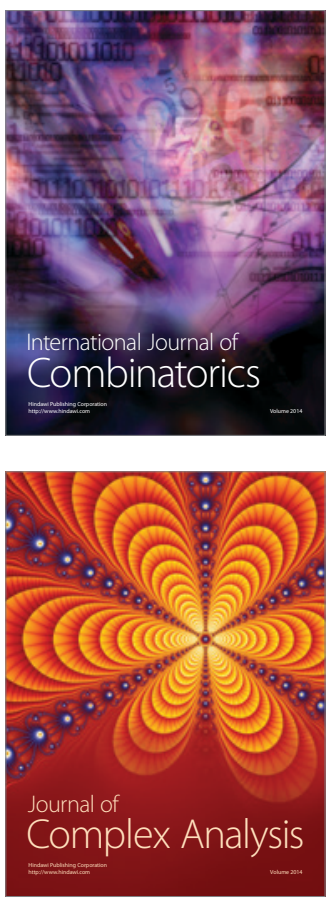

International Journal of

Mathematics and

Mathematical

Sciences
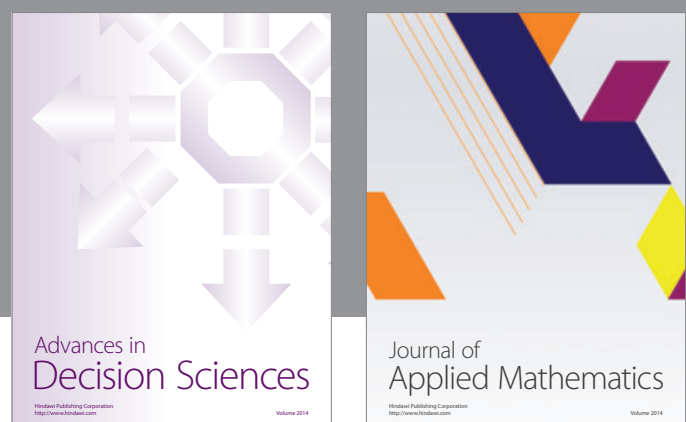

Journal of

Applied Mathematics
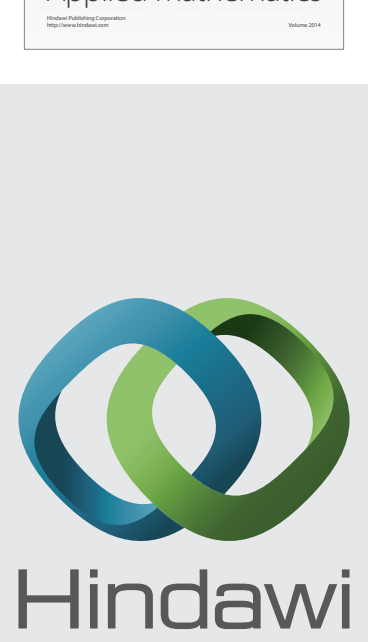

Submit your manuscripts at http://www.hindawi.com
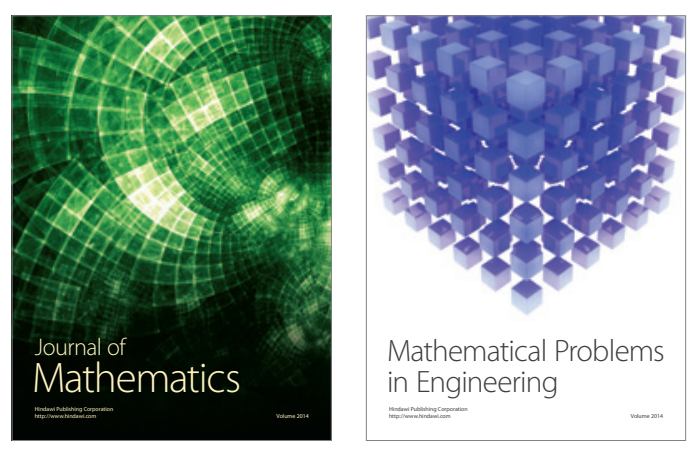

Mathematical Problems in Engineering
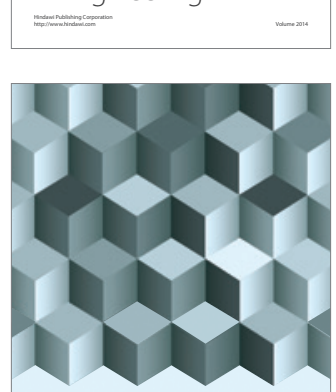

Journal of

Function Spaces
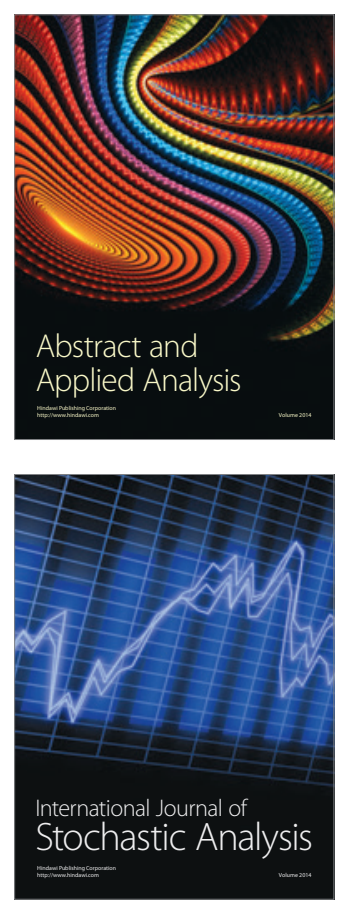

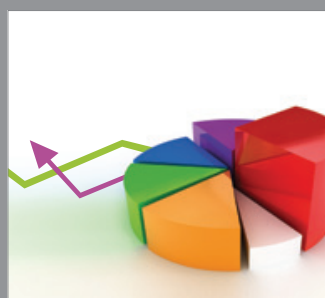

ournal of

Probability and Statistics

Promensencen
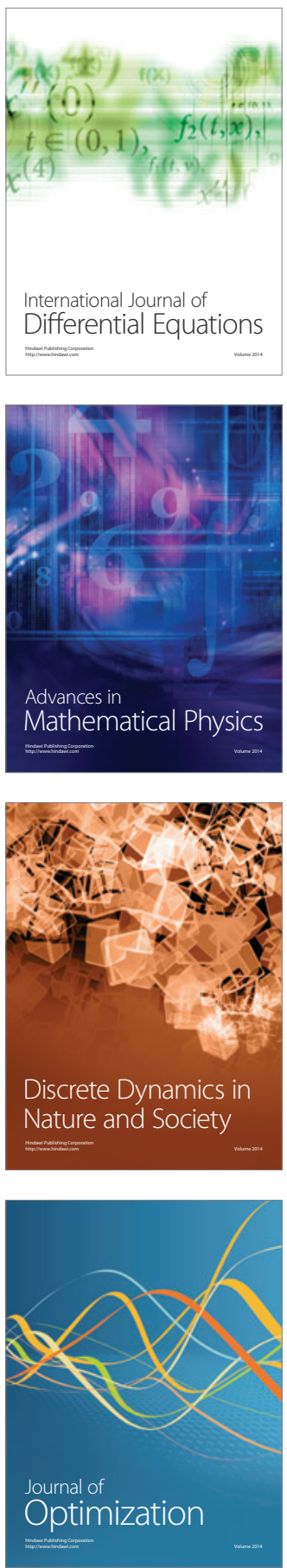